\title{
AZESMEN RESIKO BENCANA MENGGUNAKAN \\ METODE KUALITATIF \\ PADA KELURAHAN KLABULU DISTRIK MALAIMSIMSA \\ KOTA SORONG
}

Oleh: Nama

FRENGKY SREMERE

MIKA SAGRIM

FACHRUL FAUZI HAERUDDIN
Nim

20167011128

20147011064

20137011018

\begin{abstract}
Abstrak
Bencana alam sering terjadi dalam kehidupan manusia. Bencana alam yang dimaksud adalah Gempa bumi , letusan gunung, tsunami, tanah longsor, banjir dan kekeringan. untuk mengantisipasinya perlu adanya Mitigasi yang dilakukan untuk membantu ketika ada terjadi bencana alam. Pemerintah Kota Sorong suda melakukan pembangunan infrastruktur yang sesuai standar, namun sering terjadi bencana yang yang terjadi. Bencana yang sering terjadi akhir-akhir ini adalah bajin yang melanda beberapa titik ketika turungnya hujan. Upaya mitigasi untuk mendata berapa banyak korban dan kerusakan yang di akibatkan oleh banjir (bencana alam).
\end{abstract}




\section{Pendahuluan}

Mitigasi merupakan upaya atau solusi yang dilakukan oleh pemerintah dalam membantu ketika terjadi bencana Pemerintah Kota Sorong mempiliki jumlah penduduk yang semakin meningkat, sehingga dapat dipecahkan dalam bebepa Distrik dan dan Kelurahan. Pada wilayah tersebut sering terjadi bencana alam seperti tanah lonsor, banjir, kekeringan, kebakarang dan sebagainya.

Dalam tugas ini akan dibahas mengenai bencana banjir yang terjadi pada beberapa titik yang ada di Keluran Klabulu Distrik Malaimsimsa Kota Sorong dengan menggunakan metode Qualitative Risk Hazard Assessment (Metode Kualitatif)

\section{Tujuan}

Penelitian ini bertujuan untuk melakukan langkah asesmen resiko bencana yang mungkin terjadi di Kelurahan Klabulu Distrik malaimsimsa Kota Sorong,dengan mempertimbangkan beberapa bencana yang berpotensi pada daerah tersebut.

\section{Metode}

Metode yang digunakan pada penelitian ini mengikuti flowchart yang tersaji pada

Gambar 1 dibawah ini.

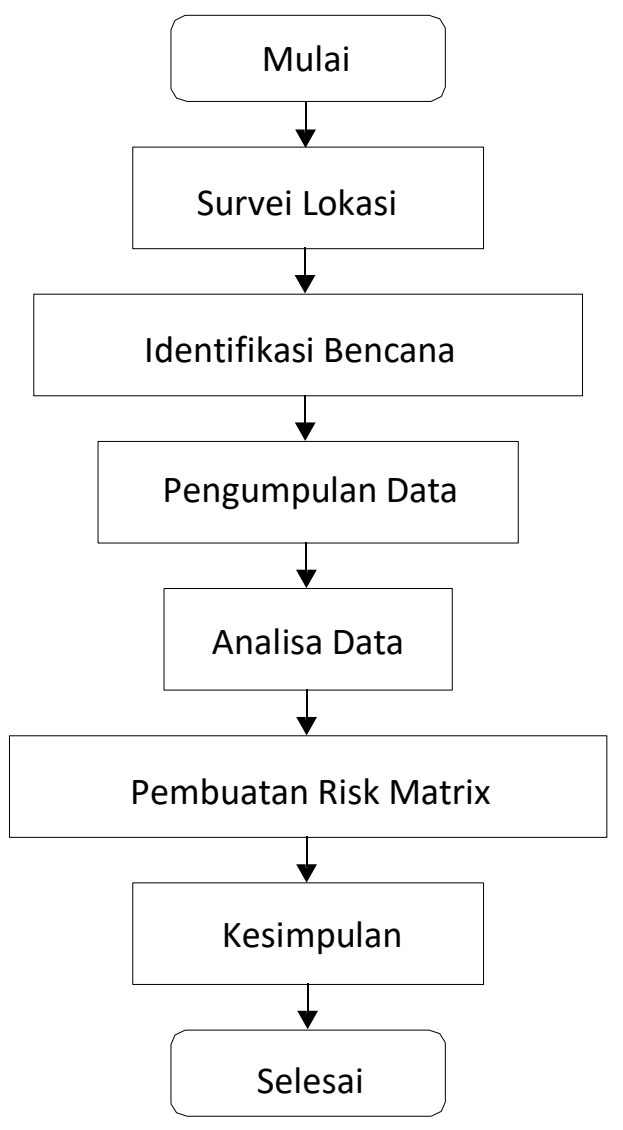

Sumber : Saputro (2018) 


\section{Hasil dan Prmbahasan}

\section{Qualitative Risk Assessment}

Jenis hazard yang akan diperhitungkan pada asesmen ini adalah gempa bumi, letusan gunung, tsunami, tanah longsor, banjir dan kekeringan. Asesmen dilakukan pada Kelurahan Klabulu, Distrik Malaimsimsa Kota Sorong Asesmen pada hazard tersebut dinilai dengan menggunakan motede Qualitative Risk Hazard Assessment.

Kelurahan Klabulu merupakan salah satu daerah sering terkena dampak banjir di beberapa titik ketika musim hujan Dan mengalami cukup banyak korban kerusakan struktur dan infrastruktur. Pengumpulan data terhadap Kelurahan Klabulu dilakukan dengan mendatangi kantor Kelurahan Kalabulu. Pengambilan data tersebut dapat dilakukan pada tanggal 29 Juni 2018.

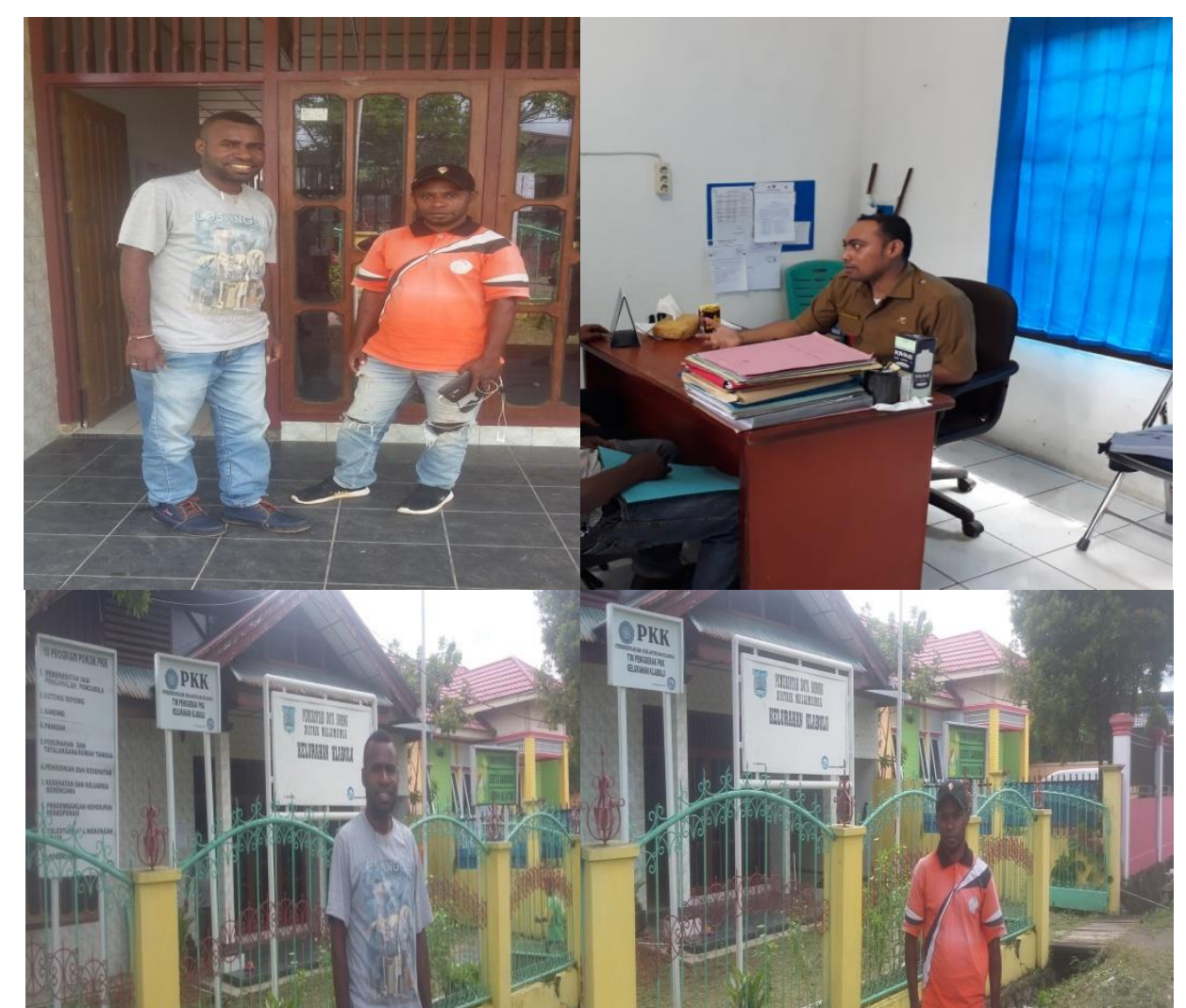


Gambar 1. Kantor Kelurahan Klabulu

Dari kantor Kelurahan Klabulu diatas dilakukan wawancara dan pengumpulan beberapa data yang berhubungan dengan Kelurahan Klabulu ini sehingga nantinya dapat digunakan dalam melakukan asesmen terhadap Kelurahan tersebut. Berikut ini disajikan data yang diperoleh:

\section{A. Luas Wilayah}

Luas wilayah Kelurahan Klabulu adalah: $\pm 1050 \mathrm{M}$

(Sumber: Wawancra Dengan Kepala Kelurahan)

\section{B. Batas Wilayah}

Batas wilayah Kelurahan Klabulu adalah:

- Sebelah Utara berbatasan dengan Kelurahan Klagete

- Sebelah Selatan berbatasan dengan Kelurahan Klasabi

- Sebelah Timur berbatasan dengan Kelurahan Sawagumu

- Sebelah Barat berbatasan dengan Kelurahan Malaingkedi

(Sumber: Data Administrasi Kelurahan Klabulu tanggal 29 Juni 2018)

\section{Jumlah Penduduk}

Data Jumlah penduduk Kelurahan Klabulu adalah

- Menurut Jenis Kelamin

Tabel 1: Jumlah Penduduk Berdasarkan Jenis Kelamin

\begin{tabular}{|c|c|c|c|c|}
\hline \multirow{2}{*}{ No } & \multicolumn{2}{|c|}{ Jenis Kelamin (Jiwa) } & \multirow{2}{*}{$\begin{array}{c}\text { Jumlah } \\
\text { Total }\end{array}$} & $\begin{array}{c}\text { Jumlah } \\
\text { KK }\end{array}$ \\
\cline { 2 - 3 } & $\begin{array}{c}\text { Laki- } \\
\text { Laki }\end{array}$ & Perempuan & & \\
\hline 1 & 4566 & 5157 & 9649 & 2205 \\
\hline & & & & \\
\hline Total & $\mathbf{4 5 6 6}$ & $\mathbf{5 1 5 7}$ & $\mathbf{9 6 4 9}$ & $\mathbf{2 2 0 5}$ \\
\hline
\end{tabular}

Sumber : Data Administrasi Kelurahan Kabulu tanggal 29 Juni 2018 
- Menurut Tingkat Pendidikan

Tabel 2: Jumlah Penduduk menurut Pendidikan

\begin{tabular}{|c|c|}
\hline $\begin{array}{c}\text { Pendidikan } \\
\text { Terakhir }\end{array}$ & Jumlah \\
\hline TK & 234 \\
\hline Sekolah Dasar & 342 \\
\hline SLTP & 564 \\
\hline SLTA & 478 \\
\hline Akademi/D3 & 154 \\
\hline Sarjana & 113 \\
\hline
\end{tabular}

Sumber: Data Administrasi Kelurahan Kabulu tanggal 29 Juni 2018

- Menurut Pekerjaan

Tabel 3: Jumlah Penduduk menurut Pekerjaan

\begin{tabular}{|c|c|}
\hline $\begin{array}{c}\text { Pendidikan } \\
\text { Terakhir }\end{array}$ & Jumlah \\
\hline PNS & 237 \\
\hline Pegawai Swasta & 321 \\
\hline ABRI & 104 \\
\hline Wiraswasta/Pedagang & 738 \\
\hline Tani & 143 \\
\hline Buruh Tani & 111 \\
\hline Pertukangan & 87 \\
\hline Jasa & 15 \\
\hline Pensiunan & 72 \\
\hline Lainnya & 109 \\
\hline
\end{tabular}

Sumber: Data Administrasi Kelurahan Kabulu tanggal 29 Juni 2018

- Jumlah Penduduk Menurut Usia

Tabel 4 : Jumlah Penduduk Menurut Usia

\begin{tabular}{|l|l|l|l|l|l|l|l|l|l|}
\hline $0-4$ & $5-6$ & $7-12$ & $13-15$ & $16-18$ & $19-25$ & $26-35$ & 36-59 & 60- & Jumlah \\
\hline & & & & & & & & & \\
& & & & & & & & & \\
\hline
\end{tabular}

Sumber: Data Administrasi Kelurahan Kabulu tanggal 29 Juni 2018

- Jumlah Penduduk Menurut Agama

Tabel 5 : Jumlah Menurut Agama

\begin{tabular}{|c|c|c|c|c|}
\hline ISLAM & KATOLIK & PROTESTAN & HINDU & BUDHA \\
\hline 2483 & 211 & 1739 & 3 & \\
\hline
\end{tabular}




\begin{tabular}{|l|l|l|l|c|}
\hline & & & & 8 \\
\hline
\end{tabular}

Sumber: Data Administrasi Kelurahan Kabulu tanggal 29 Juni 2018

D. Sarana Pendidikan

Sarana Pendidikan Kelurhan Klabulu

Tabel 6 : Jumlah Sarana Pendidikan

\begin{tabular}{|c|c|c|c|c|}
\hline TK & SD & SLTP & SLTA & P.TINGGI \\
\hline 3 & 3 & 4 & 2 & 2 \\
\hline
\end{tabular}

Sumber: Data Administrasi Kelurahan Kabulu tanggal 29 Juni 2018

\section{E. Sarana Kesehatan}

Sarana Kesehatan Kelurhan Klabulu

Tabel 7 : Jumlah Sarana Kesehatan

\begin{tabular}{|c|c|c|c|}
\hline R.SAKIT & PUSKESMAS & PUSTU & POSYANDU \\
\hline & 1 & 1 & 1 \\
& & & \\
\hline
\end{tabular}

Sumber: Data Administrasi Kelurahan Kabulu tanggal 29 Juni 2018

\section{F. Sarana Ibadah}

Sarana Ibadah Kelurhan Klabulu

Tabel 8 : Jumlah Sarana Ibadah

\begin{tabular}{|c|c|c|c|}
\hline MASJID & GEREJA & WIHARA & PURA \\
\hline 8 & 8 & & \\
& & & \\
\hline
\end{tabular}

Sumber: Data Administrasi Kelurahan Kabulu tanggal 29 Juni 2018

G. Usaha danJasa

Tabel 9 : Jumlah Sarana Ibadah 


\begin{tabular}{|c|c|c|c|c|c|c|c|c|c|}
\hline PT & CV & HOTEL & KOPERASI & TOKO & KIOS & WARTEL & BENGKEL & MEUBEL & PANTI PIJAT \\
\hline \multirow{2}{*}{10} & \multirow{2}{*}{12} & 2 & 3 & 40 & 128 & & 14 & 3 & 3 \\
\hline
\end{tabular}

Sumber: Data Administrasi Kelurahan Kabulu tanggal 29 Juni 2018

Dari data-data diatas kemudian dilakukan penentuan parameter dan indikator yang akan digunakan untuk melakukan penilaian. Berikut indicator yang digunakan.

Tabel 10. Hazard likelihood

\begin{tabular}{|c|c|c|}
\hline Rank & Description & Criteria \\
\hline 1 & $\begin{array}{c}\text { Very } \\
\text { Unlikely }\end{array}$ & $0 \%$ to $5 \%$ \\
\hline 2 & Unlikely & $6 \%$ to $15 \%$ \\
\hline 3 & Moderate & $16 \%$ to $60 \%$ \\
\hline 4 & Likely & $61 \%$ to $60 \%$ \\
\hline 5 & Very Likely & $>90 \%$ \\
\hline
\end{tabular}

Tabel 11. Fatality Indicator

\begin{tabular}{|c|c|c|}
\hline Rank & Description & Criteria \\
\hline 1 & Very Low & $0-4$ \\
\hline 2 & Low & $4-10$ \\
\hline 3 & High & $10-50$ \\
\hline 4 & Very High & $>50$ \\
\hline
\end{tabular}

Tabel 12. Injury Indicator

\begin{tabular}{|c|c|c|}
\hline Rank & Description & Criteria \\
\hline 1 & Very Low & $0-4$ \\
\hline 2 & Low & $4-50$ \\
\hline 3 & High & $50-2000$ \\
\hline 4 & Very High & $>2000$ \\
\hline
\end{tabular}

Tabel 13. Critical facilities Indicator

\begin{tabular}{|c|c|c|}
\hline Rank & Description & Criteria \\
\hline 1 & Very Low & Temporary Relocation \\
\hline 2 & Low & Closure of a few day \\
\hline 3 & High & Loss of 50\% of Capability \\
\hline 4 & Very High & Long Term Disruption \\
\hline
\end{tabular}


Tabel 14. Lifeline Indicator

\begin{tabular}{|c|c|c|}
\hline Rank & Description & Criteria \\
\hline 1 & Very Low & Temporary Interuption \\
\hline 2 & Low & Interuption of a few week \\
\hline 3 & High & Interuption of a few day \\
\hline 4 & Very High & Long Term Disruption \\
\hline
\end{tabular}

Tabel 15. Property damage Indicator

\begin{tabular}{|c|c|c|}
\hline Rank & Description & Criteria \\
\hline 1 & Very Low & Minimal Damage \\
\hline 2 & Low & Localized Damage \\
\hline 3 & High & Localized and severe \\
\hline 4 & Very High & Widespread and severe \\
\hline
\end{tabular}

Tabel 16. Enviromental Indicator

\begin{tabular}{|c|c|c|}
\hline Rank & Description & Criteria \\
\hline 1 & Very Low & Minimal Damage \\
\hline 2 & Low & Localized Damage \\
\hline 3 & High & Localized and severe \\
\hline 4 & Very High & Widespread and severe \\
\hline
\end{tabular}

Tabel 17. Economic and social Indicator

\begin{tabular}{|c|c|c|}
\hline Rank & Description & Criteria \\
\hline 1 & Very Low & Temporary Impact \\
\hline 2 & Low & Temporary and widespread \\
\hline 3 & High & Extended and widespread \\
\hline 4 & Very High & Long Term Distruption \\
\hline
\end{tabular}

Setelah menentukan parameter dan nilai yang akan digunakan kemudian langsung mengevaluasi lokasi Kelurahan Klabulu. Berdasarkan hasil survey pengumpulan data wawancara terhadap Petugas Kelurahan setempat (pak Lurah), maka data dapat disajikan seperti pada tabel berikut ini.

Tabel 18. Hasil Pengumpulan data

\begin{tabular}{|l|c|c|c|c|}
\hline \multirow{2}{*}{ Hazard } & Likelihood & \multicolumn{3}{c|}{ Impact/Consequences } \\
\cline { 2 - 5 } & Probability & fatality & Injured & Impact to Facilities \\
\hline Earthquake & $6 \%$ to $15 \%$ & 44 & 4218 & Long term disruption \\
\hline Volcano Eruption & $61 \%$ to $60 \%$ & 0 & 0 & Temporary relocation \\
\hline Tsunami & $0 \%$ to $5 \%$ & 0 & 0 & - \\
\hline
\end{tabular}




\begin{tabular}{|l|c|c|c|c|} 
Landslide & $0 \%$ to $5 \%$ & 0 & 0 & - \\
\hline Flood & $61 \%$ to $60 \%$ & 0 & 0 & - \\
\hline Drought & $16 \%$ to $60 \%$ & 0 & 0 & - \\
\hline
\end{tabular}

\begin{tabular}{|l|c|c|}
\hline \multirow{2}{*}{ Hazard } & \multicolumn{2}{c|}{ Impact/Consequences } \\
\cline { 2 - 3 } & Impact to lifelines & Property damage \\
\hline Earthquake & $\begin{array}{c}\text { Temporary Interuption } \\
\text { (Jaringan Komunikasi }\end{array}$ & Rumah dan kantor \\
\hline Volcano Eruption & Interuption of a few week & - \\
\hline Tsunami & - & - \\
\hline Landslide & - & - \\
\hline Flood & Temporary Interuption \\
& (akses Jalan) & - \\
\hline Drought & - & - \\
\hline
\end{tabular}

\begin{tabular}{|l|c|c|}
\hline \multirow{2}{*}{ Hazard } & \multicolumn{2}{c}{ Impact/Consequences } \\
\cline { 2 - 3 } & Impact to envir. & Impact to Soc. Eco \\
\hline Earthquake & Minimal Damage & - \\
\hline Volcano Eruption & Minimal Damage & - \\
\hline Tsunami & Minimal Damage & - \\
\hline Landslide & Minimal Damage & - \\
\hline Flood & Localized Damage & Temporary impact \\
\hline Drought & Localized Damage & Temporary impact \\
\hline & & Temporary and \\
Landslide & Widespread and severe & widespread \\
\hline
\end{tabular}



Berdasarkan data - data diatas kemudian diberikan penilaian kepada masing- masing hazard sebagai berikut.

Tabel 19. Penilaian Consequence

\begin{tabular}{|c|c|c|c|c|c|c|c|c|c|}
\hline \multirow[b]{2}{*}{ Hazard } & \multirow{2}{*}{$\begin{array}{c}\text { Likelihood } \\
\text { Probabilitas }\end{array}$} & \multicolumn{7}{|c|}{ Impact / Consequences } & \multirow[b]{2}{*}{ Sum } \\
\hline & & Killed & Injured & $\begin{array}{l}\text { Impact to } \\
\text { Facilities }\end{array}$ & $\begin{array}{l}\text { Impact to } \\
\text { lifelines }\end{array}$ & $\begin{array}{c}\text { Property } \\
\text { Damage }\end{array}$ & $\begin{array}{c}\text { Impact to } \\
\text { Enviroment }\end{array}$ & $\begin{array}{c}\text { Impact to } \\
\text { Social Economi }\end{array}$ & \\
\hline Earthquake & 2 & 3 & 3 & 4 & 1 & 4 & 1 & 4 & 22 \\
\hline Volcano Eruption & 4 & 1 & 1 & 1 & 2 & 1 & 1 & 1 & 12 \\
\hline Tsunami & 1 & 1 & 1 & 1 & 1 & 1 & 1 & 1 & 8 \\
\hline Landslide & 1 & 1 & 1 & 1 & 1 & 1 & 2 & 1 & 9 \\
\hline Flood & 4 & 1 & 1 & 1 & 1 & 1 & 2 & 1 & 12 \\
\hline Drought & 3 & 1 & 1 & 1 & 1 & 1 & 4 & 2 & 14 \\
\hline
\end{tabular}


Dari tabel kemudian dibuatkan plot matrik antara kemungkinan kejadian ( Likelihood) dengan Dampak yang ditimbulkan ( Concequence) seperti pada gambar 2 berikut ini.

\begin{tabular}{|c|c|c|c|c|c|c|}
\hline & Likelihood/ & \multicolumn{5}{|c|}{ Severity of impact/Consequences } \\
\hline & Probability & Minimal & Slight & Moderate & Severe & Very Severe \\
\hline 5 & Very Likely & & & & & \\
\hline 4 & Likely & & Flood & $\begin{array}{l}\text { Volcano } \\
\text { Eruption }\end{array}$ & & \\
\hline 3 & Moderate & & & Drought & & \\
\hline 2 & Unlikely & & & & EarthQuak & \\
\hline 1 & Very Unlikely & & $\begin{array}{l}\text { Tsunami } 8 \\
\text { Landslide }\end{array}$ & & & \\
\hline & Impact Rank & Very Low & Low & Moderate & High & Very High \\
\hline & Score & $1-6$ & $7-12$ & $13-18$ & $19-23$ & $24-28$ \\
\hline
\end{tabular}

Gambar 2. Risk matrik di Desa Imogiri 


\section{Kesimpulan}

Dari hasil risk assessment dengan menggunakan metode qualitative risk hazard assessment diperoleh hasil bahwa pada Kelurahan Klabulu Distrik Malaimsimsa Kota Sorong adalah Banjir akibat oleh hujan. Banjir walaupun tidak menimbulkan korban jiwa tetapi karena kala ulang (return period) yang terjadi sekirar membuat banjir merupakan suatu hazard yang harus serius ditangani. Gempa bumi merupakan hazard kedua yang mempunyai potensi resiko besar.

Dari pengambilan data diperoleh fakta bahwa korban banyak terjadi pada anak-anak dan juga orang lanjut usia. Hal ini dapat disimpulkan bahwa kerentanan terhadap anak-anak dan orang lanjut usia sangat tinggi. Sehingga perlu dilakukan sosialisasi bagaimana upaya penyelamatan apabila terjadi Banjir sehingga tidak banyak menimbulkan banyak korban jiwa karena menggingat sifat bencana sering terjadi. Sedangkan bencana-bencana lain yang terjadi tidak terlalu signifikan mengingat kalau dibandingkan dengan hazard-hazard

lainnya. 


\section{DaftarPustaka}

Columbia,British(2004).Hazard,Risk,andVurnerabilityAnalysisToolKit.Provincial EmergencyProgram.

Saputro,I.T. (2018).Analisis PerbandinganKurvaHazard PadaKotaBandaAcehDengan

Sumber GempaSesar SeulimeumDanMenggunakanBeberapaFungsiAtenuasi.

Saputro, I. T. (2018). ASESMEN RESIKO BENCANA MENGGUNAKAN METODE KUALITATIF PADA DESA IMOGIRI.

Widodo(2013).NaturalHazardRiskAssessment.BahanKuliah.UniversitasIslamIndonesia.Yogya karta

https://www.google.com/m

$a p$ 